\title{
Surgical treatment of post-cricoid carcinoma
}

\author{
KEN NETH MULLARD \\ From the Wessex Cardiac and Thoracic Unit, Chest Hospital, Southampton
}

\begin{abstract}
Experience of the treatment of 20 patients with post-cricoid carcinoma is reported, and the conclusion reached was that radical surgery is the best form of treatment, using radiotherapy to deal with subsequent developments. The surgical procedure used has been a single-stage pharyngolaryngectomy and total oesophagectomy with restoration of continuity by a posterior mediastinal colon transplant.
\end{abstract}

In 1966 Hobbs and Mullard described a surgical procedure which they had developed for the treatment of post-cricoid carcinoma. This consisted of a total excision of the oesophagus from the midpharynx to the stomach, together with the whole of the larynx and upper trachea, and immediate restoration of the alimentary tract by a graft of the left half or two-thirds of the transverse colon, pedicled on the ascending branch of the left colic artery. The graft was placed in the posterior mediastinum in the bed of the resected oesophagus, except where it passed laterally to the arch of the aorta. The operation was done in a single stage, except in a few patients in whom it was necessary to establish a gastrostomy to improve nutrition a week or two before operation. The operation was done through a left thoracoabdominal incision and a cervical flap incision. Originally the two stages were performed consecutively, but more recently they have been done synchronously.

Experience since that paper has shown that this is a satisfactory procedure for dealing with this singularly difficult disease. The present paper describes experiences of cases of post-cricoid carcinoma treated by this method and by other means.

Twenty cases have been seen since 1963 -not a great number, but this is not a very common disease. Table I shows the distribution by age and sex in this series. Table II shows the type of treatment given. Two patients were neither operated on nor treated by radiotherapy. One was a woman of 76 with cerebral atheroma, who was given a gastrostomy to improve her nutrition in the hope that she could be brought to a fit state for operation; but this hope was never realized. The other was a man of 65 who had a short history of dysphagia and who had a huge retropharyngeal mass, originating in the crico-pharyngeus, and massive gland involvement in the neck. He diects in the course of a few weeks. The five cases treated by radiotherapy confirm the view that this: is not satisfactory. Three of these patients, when first seen, showed infiltration in the tissue planesof the neck or gland involvement or had downward involvement of the trachea to the extent that a tracheostomy could not have been established below the growth and were deemed beyond thes scope of resection and referred for a course of radiotherapy. None obtained any relief and aln died within three or four months. Radiotherapy was given by skilled radiotherapists using modern $\vec{F}$ cobalt 60 or caesium bomb apparatus, so that they received the best possible radiotherapy. The? other two had had radiotherapy before beingo referred for a surgical opinion. Both of these were

T A B L E I

DISTRIBUTION BY AGE AND SEX IN 20 CASES OF POSTCRICOID CARCINOMA

\begin{tabular}{c|c||c|cc|}
\hline $\begin{array}{c}\text { No. of } \\
\text { Male Cases }\end{array}$ & $\begin{array}{c}\text { Age } \\
\text { (yrs) }\end{array}$ & $\begin{array}{c}\text { No. of } \\
\text { Female Cases }\end{array}$ & \multicolumn{3}{|c|}{ Age (yrs) } \\
\hline 6 & 24 & 14 & 33 & 57 \\
& 48 & & 34 & 57 \\
& 62 & & 41 & 59 \\
& 62 & & 42 & 59 \\
& 63 & & 48 & 70 \\
& 65 & & 52 & 75 \\
\hline
\end{tabular}

T A B L E I I

TREATMENT GIVEN IN 20 CASES OF POST-CRICOID CARCINOMA

\begin{tabular}{c|c}
\hline \multicolumn{1}{c|}{ Treatment } & No. \\
\hline $\begin{array}{c}\text { Operation } \\
\text { Pre-op. radiotherapy } \\
\text { Post-op. radiotherapy } \\
\text { No radiotherapy }\end{array}$ & 3 \\
Radiotherapy only & 13 \\
\hline None & \\
\hline
\end{tabular}


originally diagnosed as having carcinoma in a pharyngeal pouch. One of them certainly had had such a carcinoma and the other had probably had an ordinary post-cricoid carcinoma. The one with post-cricoid carcinoma had an inhalation pneumonia when admitted and died shortly after admission. The other had had carcinoma in a pharyngeal pouch. She had obtained some months of relief following irradiation, but progressive fibrosis of the oesophagus and larynx led to recurrent dysphagia. She was treated by dilatation and intubation and she died 15 months after the diagnosis of carcinoma had been made. No evidence of carcinoma was found following the radiotherapy. The recurrent dysphagia was due to fibrosis in the oesophagus.

Our experience of radiotherapy had therefore been an unhappy one. Four out of five cases were unaffected, and in the fifth, although the tumour was apparently ablated by the radiotherapy, this was only at the price of oesophageal fibrosis and recurrent dysphagia.

Of the 13 patients operated upon (Table III), three had had radiotherapy before being referred for surgery, and these showed the same transitory relief or lack of relief from radiotherapy as those previously mentioned. Two of them had a

T A B L E I I I

RESULTS OF 13 OPERATION CASES

\begin{tabular}{l|c|c}
\hline $\begin{array}{c}\text { Operation } \\
\text { Result }\end{array}$ & $\begin{array}{c}\text { Interval } \\
\text { Post-op. }\end{array}$ & Remarks \\
\hline $\begin{array}{c}4 \text { Alive and } \\
\text { well }\end{array}$ & $\begin{array}{r}4 \mathrm{yr} \\
15 \mathrm{mth} \\
9 \mathrm{mth} \\
6 \mathrm{mth}\end{array}$ & \\
\hline 3 Died & $\begin{array}{r}18 \mathrm{mth} \\
9 \mathrm{mth} \\
8 \mathrm{mth}\end{array}$ & Tracheal recurrence \\
\hline 1 Died & $3 \mathrm{mth}$ & Fibrosis of graft \\
\hline 1 Died & $3 \mathrm{mth}$ & Renal failure \\
\hline 3 Died & After operation & $\begin{array}{l}1 \text { Respiratory failure ; } \\
\text { Tracheal necrosis; } \\
1 \text { Pleural effusion }\end{array}$ \\
\hline 1 Died & After thoracotomy & \\
\hline
\end{tabular}

recurrence of dysphagia two months after the completion of their course and the third after eight months. In this patient the growth had begun in the left vocal cord and had recurred in the post-cricoid region. It was a slow-growing tumour and symptoms had been present for over 18 months before operation.

All these did badly. In one there was loss of elasticity in the skin of the neck following opera- tion, leading to dysphagia. Malignant lymph nodes developed in the neck six months after operation and failed to respond to radiotherapy ; the patient died 10 months after operation. The second was found to have, at the time of operation, a friable posterior wall of the trachea and a spread of growth to the carotid sheath. The friable state of the trachea led to an unsatisfactory tracheostomy, and a cuffed endotracheal tube had to be maintained in the tracheostomy for a week or so after operation; this caused pressure necrosis of the posterior wall of the trachea and the anterior wall of the graft, and a fistula, $2-3 \mathrm{~cm}$. in diameter, developed. The fistula became clean and healthy and this patient was due to have a plastic repair of the fistula, but he died of renal failure before the operation could be done. He had had renal disease before the operation. The third patient had had an intensive course of radiotherapy which caused severe destruction of the trachea. A tracheostomy had to be carried out as an emergency before operation because of narrowing of the trachea and sloughing of the mucosa, and at operation the trachea was found to be shortened, the carina being drawn up almost to the thoracic inlet, pulling up the aortic arch with it and causing a good deal of crowding of structures in the root of the neck. The stenosis of the trachea and the slough of the mucosa affecting its whole length caused her death three days after operation. The fourth patient was given radiotherapy before operation and was more satisfactory. She was originally diagnosed as having a pyriform fossa growth in November 1965 . She was treated on the Cobalt Unit in December 1965 and January 1966, but the growth had recurred in the post-cricoid region and was operated upon in May 1966. A year later, in June 1967, a lymph node developed at the angle of the jaw and was successfully treated by further irradiation.

In distinction to the patients treated by radiotherapy alone or before surgery, four were given radiotherapy after operation to deal with nodes that had developed in the neck, and in three a satisfactory response was achieved but radiotherapy has been ineffective in dealing with a tracheal recurrence.

There are some aspects of the surgical procedure itself which may be of interest. The first concerns the colon transplant. If there have been previous abdominal operations, and particularly if there has been some infection associated with these operations, the preparation of the graft is likely to be difficult. One of the patients who died after operation had previously had a partial 
FIG. 1. The mesenteric veins. The transplant of colon, taken from the left half of the transverse colon and the splenic flexure, drains through a branch of the inferior mesenteric vein (cut in the diagram), which, when the graft is in position in the mediastinum, passes behind the stomach and anterior to the pancreas to enter the inferior mesenteric vein, which then passes posterior to the pancreas to enter the lienal vein. Thus the venous drainage of the transplant encircles the pancreas. (Diagram from Gray's Anatomy, 24th edition, by courtesy of Longmans, Green \& Co.) 
gastrectomy, a laparotomy, an oophorectomy, and two pelvic floor repairs. Following operation there was a persistent effusion of fluid into the left chest with which one could not keep pace by aspiration and drainage. Fluid tracked into the neck and was drained from there. The excessive loss of fluid led to a loss of electrolyte control, and the patient died as a result. No cause for this excessive effusion was found at necropsy, but it seems probable that it was due to venous obstruction. The venous drainage of the graft takes a circuitous course almost encircling the pancreas (Fig. 1). This raises a point so far as the operation is concerned. There is nothing to be gained by taking much of the descending colon for the graft, because the upper part of the descending colon cannot be moved upwards very much. One should take a little, dividing the colon just below the splenic flexure, and this can easily be transposed to the back of the fundus. It is best not to mobilize the descending colon in order to make a tension-free anastomosis to restore continuity of the colon. Although the descending colon comes readily to hand through a left thoraco-abdominal incision, one runs the risk of damage to the left colic and inferior mesenteric veins or of obstruction by mobilization of the descending colon. It is best to bring the ascending colon across from the right side, although it is more difficult of access. The patient who died of fibrosis of the graft was another example of obstruction of the venous return. At the time of operation a small submucous haematoma developed during the anastomosis of the graft and the stomach. It did not appear to be of much significance at the time, but about 10 to 12 days after operation, after a few days of satisfactory feeding, she regurgitated a slough of the mucosa of the graft. This was everted during regurgitation and was eventually cut away from the pharyngo-colic anastomosis (Fig. 2). This submucous haematoma noted at operation spread, and it probably spread because of venous obstruction. Although the entire mucosa of the graft sloughed, the graft itself remained patent and she was able to swallow a semi-liquid diet until she died three months later. The delicacy of the venous drainage in these grafts is a point in favour of placing the graft in the mediastinum under direct vision. Any procedure in which the graft is pulled blindly through the thorax is bound to have a high proportion of failures from damage to the vascular pedicle and especially to the veins. Another advantage of placing the graft in the mediastinum and passing the upper end to one's colleague operating in the neck is that the true effective length of the graft can be used. If one pulls on one end of one of

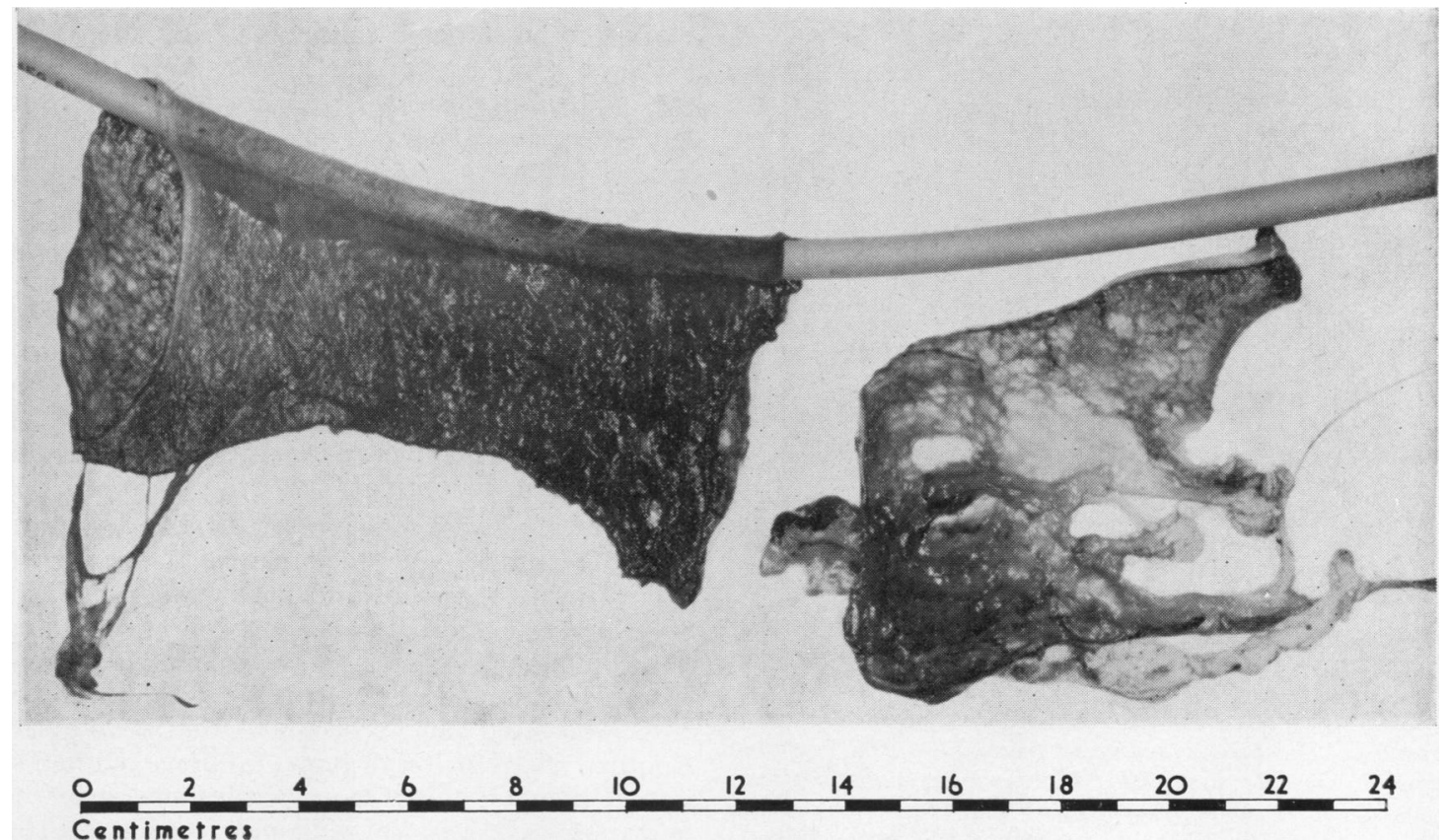

FIG. 2. Part of a slough of the mucosa of a colon transplant. 
these grafts, that end will stretch until it becomes taut, dangerously so, before the next segment begins to elongate. This is clearly undesirable, but it must happen in any blind pull-through technique; but if one places the graft in the mediastinum, one can ensure that the whole length of it is evenly extended, without stretching anywhere, and one gets plenty of graft by this method (Fig. 3).

Downward spread into the trachea and postoperative recurrence in the trachea has been the great trouble. Three of the late deaths have been due to this. It has caused the rejection of one patient for operation and it has given rise to technical difficulties at operation or soon after in two others. In one, in whom the lower limit of the growth was not defined before operation, the operation itself had to be abandoned because

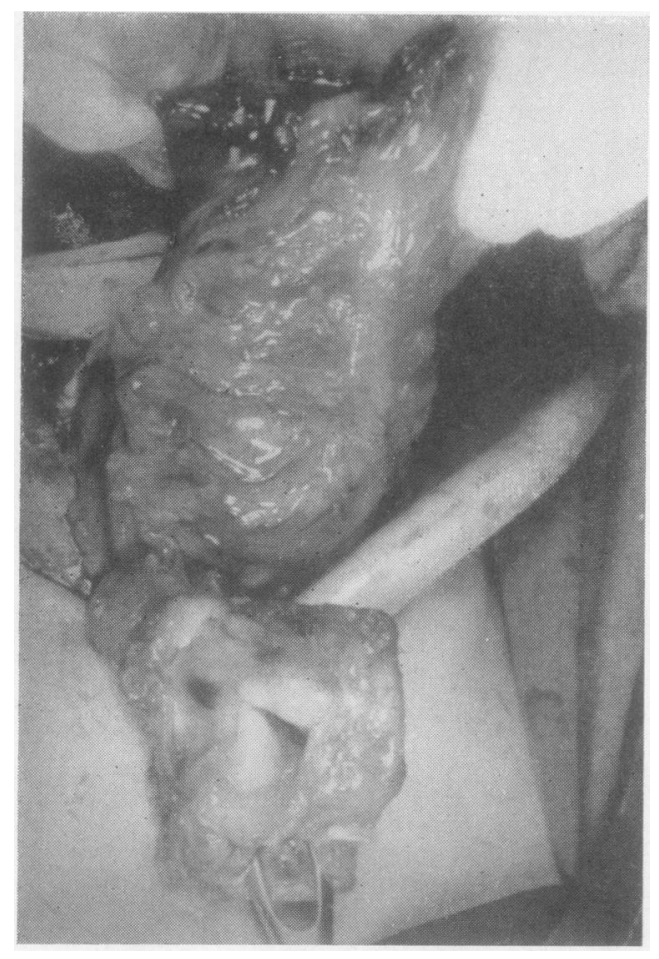

FIG. 3. The colon transplant has been placed in the posterior mediastinum and its upper end brought out through the cervical incision above the endotracheal anaesthetic tube, which has been inserted into the partially divided trachea. The larynx and upper trachea are held in tissue forceps over the chest wall. The oesophagus cannot be seen. The colon transplant has sufficient length that it can easily be drawn up over the chin, giving more than adequate length for a tension-free anastomosis to the mid-pharynx. it was found that growth extended down the trachea and oesophagus to the carina. This recur $\frac{5}{5}$ rence in the trachea would also affect the oeso $\overline{\bar{n}}$ phagus but for the total oesophagectomy. Experi ence of oesophagectomy for carcinoma at othe? sites has shown that longitudinal spread is usually extensive, and for this reason total oesophagectomy will give better results than local excisions confined to the neck. The use of a free bowel graft, usingw vascular anastomosis, has been proposed. The elegant small vessel anastomosis apparatus now available seems to offer a simple solution to the technical problems posed by these cases but though the vascular anastomoses of the graft mays be highly satisfactory, the procedure will probably be ineffective because of inadequate resection of the oesophagus. An adequate resection of thes oesophagus must be no higher than the level of the bifurcation of the trachea, and the subsequen $\mathbb{D}^{\circ}$ anastomosis of the graft and the oesophagus can not be done at that level from the neck. If less oesophagus than this is removed, oesophageato recurrence is likely, always provided that the anastomosis heals in the first instance, because the blood supply of the upper third of the oesophagus is from the inferior thyroid arteries and all this will have gone in the resection of the larynx hypo-pharynx, and upper end of the oesophagus $\frac{0}{D}$

The association of anaemia and crico $\cong$ pharyngeus spasm and web formation and its $\overrightarrow{\vec{s}}$ relation to post-cricoid carcinoma have often been discussed. Only one of the 20 cases here recorded had a previous history of anaemia, of which no. details are available, six years before her admis sion.

Radical excision of the pharynx and larynx be $\frac{x}{2}$ tween the hyoid and the thoracic inlet, with the exception of the carotid sheaths, is bound to leads to hypoparathyroidism. Four cases showed frank tetany with serum calcium levels down to $5 \cdot 6 \mathrm{mg}$. $/ 0$ $100 \mathrm{ml}$. This was treated by intravenous calcium? and invariably, soon after normal mouth feeding had been resumed, tetany ceased and the calcium
level returned to normal.

A striking feature has been the lack of post $\tilde{O}^{\circ}$ operative shock and the relatively easy post operative management of these patients. There have, it is true, been four deaths following operation, but none was due to the magnitude of the operation itself. One patient was found to be inoperable and the procedure was abandoned: Another died of respiratory failure; he had severe bilateral inhalation pneumonia prior to operation and was, in retrospect, unsuitable for surgery (Fig. 4). One died of tracheal necrosis and $\underset{0}{O}$ 


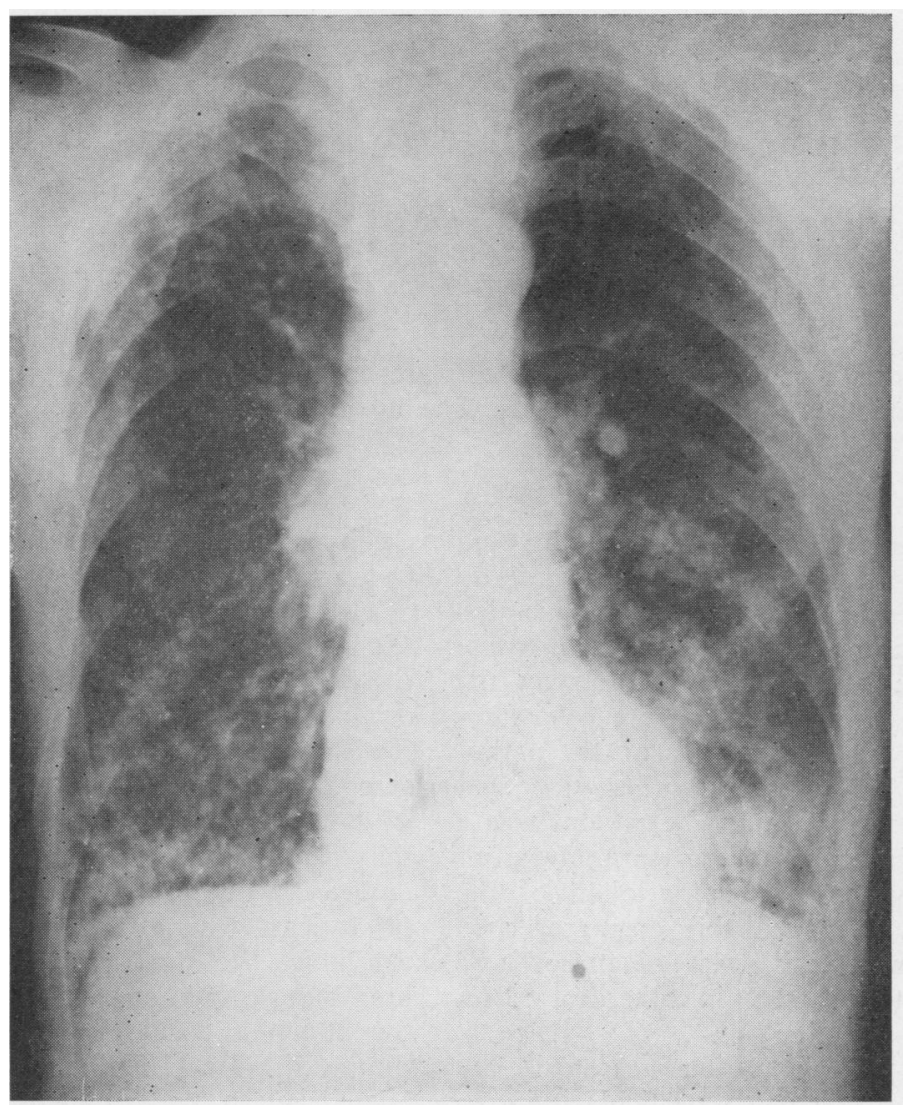

FIG. 4. Chest radiograph before operation shows gross bilateral inhalation pneumonia.

once again, this was a virtually hopeless proposition and death was not the result of the operation but of the preceding radiotherapy. Only one died of the direct effect of the operation-the patient with persistent pleural effusion which was, in all probability, due to venous obstruction.

Experience of these cases suggests that it is best to use radical surgery as a first line of attack, and that radiotherapy is best used should the tumour recur. One should not be deterred by the apparent magnitude of the surgical procedure into using radiotherapy or a lesser surgical procedure in the first place, for such measures are likely to be transient in their effects. The major surgical procedure is, in fact, well tolerated by patients in a reasonably good condition; and most of these patients are in good condition at the onset of the disease.

\section{REFERENCE}

Hobbs, C. Remington, and Mullard, K. (1966). The treatment of post-cricoid carcinoma by single stage pharyngolaryngectomy and colon transplant. J. Laryng., 80, 1193. 